\title{
PROPERTY VALUATION UNDER UNCERTAINTY. SIMULATION VS STRATEGIC MODEL
}

\author{
Wiesław MESZEK \\ Department of Construction Engineering and Management, Poznan University of Technology, \\ 60-965 Poznan, Poland \\ E-mail: wieslaw.meszek@put.poznan.pl
}

Received 10 January 2011; accepted 5 December 2011

\begin{abstract}
Uncertainty is a real and universal phenomenon in property valuation. The sources of uncertainty premises originate in the market's specific character, particularly in its informative inefficiency. The degree of uncertainty will vary according to the level of market activity. The result of this uncertainty for the process of property valuation is the impossibility of the measurement of the market value weights and unknown reliability of the real estate transaction prices. In practice, the market value of each property is based on prices under the assumption that the market is efficient; however in reality, prices do not fully reflect the available information. The reasons are, among others, low transparency of the market and confidentiality of transactions let alone the market imperfections. In terms of information inefficiency of the real estate market, statistical methods are ineffective for property valuation, therefore there is a need to use methods and models taking uncertainty into consideration. This paper looks at the way in which uncertainty can be incorporated into the explicit model of sales comparison approach (pairwise comparison method). One model focuses on the application of the Monte-Carlo simulation and the other on the game theory.
\end{abstract}

KEYWORDS: Property; Property valuation; Pairwise comparison method; Simulation; Game theory; Efficient market hypothesis; Uncertainty

REFERENCE to this paper should be made as follows: Meszek, W. (2013) Property valuation under uncertainty. Simulation vs strategic model, International Journal of Strategic Property Management, 17(1), pp. 79-92.

\section{INTRODUCTION}

Property valuation is the process of estimating price under uncertainty that is a real and universal phenomenon in valuation. The degree of uncertainty will vary according to the level of market activity and will vary significantly; these variations can arise because of the inherent features of the property or the information available to the valuer. These input uncertainties will translate into an uncertainty with the output value - the price estimate. One of the major problems is that valuation models are based on comparable information and rely on single inputs. The input variables are uncertain and will have no probability distribution that pertains to each of them.

The sources of uncertainty premises originate in the market specific character, particularly in its informative inefficiency.

According to Fama (1965) An efficient market is defined as a market where there are large numbers of rational profit-maximizers actively competing, with each trying to predict future market values of individual securities, and where important current information is almost 
freely available to all participants. In an effective market, competition among the many intelligent participants leads to a situation where, at any point in time, actual prices of individual securities already reflect the effects of information based both on events that have already occurred and on events which the market expects to take place in the future.

It means, that on an efficient market, prices always fully reflect the available information (Fama, 1970).

The Efficient Market Hypothesis (EMH) deals with three types of market efficiency:

- weak form efficiency - the information set is that the market index reflects only the history of prices or profit returns (of the same financial instruments),

- semi-strong form efficiency - the information set includes most information known to all market participants,

- strong form efficiency - the information set includes all information known to any market participant.

There is no doubt, that in the case of the real estate market, exhibiting low transparency, confidentiality of transactions, and most importantly imperfections, weak form efficiency can be considered at best.

Information inefficiency of the real estate market is confirmed among others by Wiśniewski's (2007) research, where he underlines (based on local real estate markets in Poland), that the achieved results incline to conclude, that the analysed real estate markets are not efficient in terms of the weak EMH hypothesis.

Uncertainty, as an objective fact, has been noticed by well-known organizations associating property valuers. Some of them made initial actions aiming at creating standards, to describe the methods of property valuation under uncertainty.

In the study conducted by Royal Institution of Chartered Surveyors (RICS) recommendations have been created:

- Mallinson Recommendation 34: Common professional standards and methods should be developed for measuring and expressing valuation uncertainty (The Mallinson Report, 1994),

and

- Carsberg Recommendation 15: RICS should commission work to establish an acceptable method by which uncertainty could be expressed in a manner that will be helpful and will not confuse users of the valuation. RICS should also seek to agree with appropriate representative bodies of those commissioning and using third party valuations the circumstances and format in which the valuer would convey uncertainty (The Carsberg Report, 2002).

The objective of both the Mallinson (The Mallinson Report, 1994) and Carsberg (The Carsberg Report, 2002) recommendations is to establish an acceptable method by which uncertainty could be expressed in a uniform and useful manner. This requires agreement on both the expression of the uncertainty of the inputs and agreement on the output information that must be conveyed with each valuation.

Investigations into the expression of uncertainty in property valuations were made by, i.a., Mallinson and French (2000), Siniak and d'Amato (2003), Joslin (2005), French and Gabrielli $(2004,2005,2006)$ and Atherton et al. (2008).

The majority of the above-mentioned authors prefer simulation models that allow the user to incorporate uncertainty into the analysis in a relatively simple form (each input is defined by the chosen probability density function).

As shown by French and Gabrielli (2004) the sources of uncertainty can be identified and described in a practical manner, and, above all, the process of identification and description will greatly assist many clients and will improve the content and the credibility of the valuer's work. French and Gabrielli (2004) distinguish two kinds of uncertainty:

- normal uncertainty, as a universal and an unsurprising fact of property valuation, 
- abnormal uncertainty, that arises when some particular condition of the market or the property leads to the valuer being unable to value with the confidence of accuracy that might normally be expected.

In practice, however, as indicated by Kucharska-Stasiak (2008), the property valuation is based on prices under the assumption that the market is efficient; however in reality, prices do not fully reflect the available information about attributes of comparable properties. In terms of information inefficiency of the real estate market, statistical methods are ineffective for the property valuation, hence the need to use methods and models taking into account uncertainty. Uncertainty, as an objective state in the valuation process, might be modelled with the use of different methods together with different kinds of models. In this paper, the discussion has been raised on the usefulness of simulation models and strategic models based on game theory. In those two cases, pairwise comparison method was used, whose principles were further discussed in Section 2.

\section{MODELLING OF SALES COMPARISON APPROACH (PAIRWISE COMPARISON METHOD)}

The sales comparison approach estimates the value of a subject property from the sales prices of the comparable properties. Sales prices of comparable properties are adjusted for differences from the subject property; the adjustments are derived from local sales analysis.

In the pairwise comparison method, the general formula can finally take the following form:

$$
V=\frac{\sum_{j=1}^{n} C_{j k} \cdot q_{j}}{\sum_{j=1}^{n} q_{j}},
$$

of which: $V$ - Market Value of the subject property; $C_{j k}-j^{\text {th }}$ comparable property sales price, adjusted by the sum of adjustments; $q_{j}-j^{\text {th }}$ comparable sales price reliability, where, in practiced standardization $\sum_{j=1}^{n} q_{j}=1$; above formula (1) is simplified usually to the form of:

$$
V=\sum_{j=1}^{n} C_{j k} \cdot q_{j}
$$

where:

$$
C_{j k}=C_{j}+\sum_{i=1}^{m} \Delta C_{i j}
$$

of which: $C_{j}-j^{\text {th }}$ comparable property sales price, $(j=1 \ldots n) ; \Delta C_{i j}$ - amount adjustment, concerning the $j^{\text {th }}$ comparable property sales price and the $i^{\text {th }}$ attributes including their weights $p_{i}$ :

$$
\Delta C_{i j}=\left(C_{\max }-C_{\min }\right) \cdot p_{i} \cdot \frac{a_{i w}-a_{i j}}{a_{i \max }-a_{i \min }},
$$

where: $p_{i}-i^{\text {th }}$ attributes' weight; $C_{\max }-$ maximum price of the comparable property; $C_{\min }-$ minimum price of the comparable property; $a_{i w}$ - assessment of $i^{\text {th }}$ attribute of the subject property; $a_{i j}$ - assessment of $i^{\text {th }}$ attribute of $j^{\text {th }}$ comparable property; $a_{i \text { min }}$ - the worst assessment of $i^{\text {th }}$ attribute among comparable properties; $a_{i \max }-$ the best assessment of $i^{\text {th }}$ attribute among comparable properties.

Data presented in Table 1 were used to show the process of modelling property valuation under uncertainty (shown in Sections 3 and 4).

Using classic rules of pairwise comparison method, represented by formula (1-4), and taking into consideration identical weight of attributes and identical sales price reliability, following the valuation, the value of $V=79.79$ EUR/ $1 \mathrm{~m}^{2}$ (Table 2) results. 
Table 1. The basis for comparable properties and their assessment

\begin{tabular}{|c|c|c|c|c|c|c|}
\hline \multirow[t]{3}{*}{ Attribute } & \multirow{3}{*}{$\begin{array}{l}\text { Weight of } \\
\text { attributes }\end{array}$} & \multicolumn{5}{|c|}{ Property assessment (in points) } \\
\hline & & \multirow{2}{*}{$\begin{array}{l}\text { Subject } \\
\text { property }\left(a_{i w}\right)\end{array}$} & \multicolumn{4}{|c|}{ Comparable properties $\left(a_{i j}\right)$} \\
\hline & & & $N_{1}$ & $\mathrm{~N}_{2}$ & $N_{3}$ & $N_{4}$ \\
\hline Attribute 1 & $p_{1}$ & 3 & 4 & 2 & 1 & 3 \\
\hline Attribute 2 & $p_{2}$ & 2 & 1 & 4 & 5 & 1 \\
\hline Property sales price $C_{j}\left(\mathrm{EUR} / 1 \mathrm{~m}^{2}\right)$ & & & 70 & 80 & 90 & 80 \\
\hline Sales price reliability & & & $q_{1}$ & $q_{2}$ & $q_{3}$ & $q_{4}$ \\
\hline
\end{tabular}

Table 2. Property valuation according to pairwise comparison method represented by formula (1-4)

\begin{tabular}{|c|c|c|c|c|c|c|c|c|}
\hline Attribute & $\begin{array}{l}\text { Weight of } \\
\text { attributes }\end{array}$ & $\left(C_{\max }-C_{\min }\right) p_{i}$ & $a_{i \max }-a_{i \text { min }}$ & & $N_{1}$ & $N_{2}$ & $N_{3}$ & $N_{4}$ \\
\hline \multirow[t]{2}{*}{ Attribute 1} & 0.5 & 10 & 3 & $a_{i w}-a_{i j}$ & -1 & 1 & 2 & 0 \\
\hline & & & & $\Delta C_{i j}$ & -3.33 & 3.33 & 6.67 & 0.00 \\
\hline \multirow[t]{2}{*}{ Attribute 1} & 0.5 & 10 & 4 & $a_{i w}-a_{i j}$ & 1 & -2 & -3 & 1 \\
\hline & & & & $\Delta C_{i j}$ & 2.50 & -5.00 & -7.50 & 2.50 \\
\hline$\sum^{2} \Delta C$. & & & & & -0.83 & -1.67 & -0.83 & 2.50 \\
\hline \multicolumn{2}{|c|}{$C_{j k}=C_{j}+\sum_{i=1}^{2} \Delta C_{i j}$} & & & & 69.17 & 78.33 & 89.17 & 82.50 \\
\hline \multicolumn{2}{|l|}{$q_{j}$} & & & & 0.25 & 0.25 & 0.25 & 0.25 \\
\hline$V=\sum_{j=1}^{4} C_{j k} \cdot q$ & & & & & \multicolumn{2}{|c|}{$79.79 \mathrm{EUR} / 1 \mathrm{~m}^{2}$} & & \\
\hline
\end{tabular}

\section{MODELLING OF PROPERTY VALUATION UNDER UNCERTAINTY USING SIMULATION}

The use simulation models (Monte Carlo Simulation) that can be solved with the use of Crystal Ball software is a subject of various papers including Mallinson and French (2000), French and Gabrielli (2004, 2005, 2006).

Mallinson and French (2000) argued that there were six items of information that should be conveyed when reposting uncertainty:

- the single figure valuation - market value $(V)$,

- the range of the most likely observation $<V_{a}, V_{b}>$ (e.g. 5 per cent either side of $\left.V\right)$,
- the probability of the most likely observation $P<V_{a}, V_{b}>$,

- the range of higher probability $P<V_{c}$, $V_{d}>$,

- the range of 100 per cent probability $P$ $<V_{\text {min }}, V_{\text {max }}>$,

- the skewness of probabilities.

The above suggestions can be presented as shown in Figure 1.

French and Gabrielli (2005) made a certain modification of this viewpoint and indicated that the sufficient range of data includes:

- the single figure valuation - market value $(V)$,

- the certainty range at 5 per cent, 10 per cent, 50 per cent and 100 per cent, 


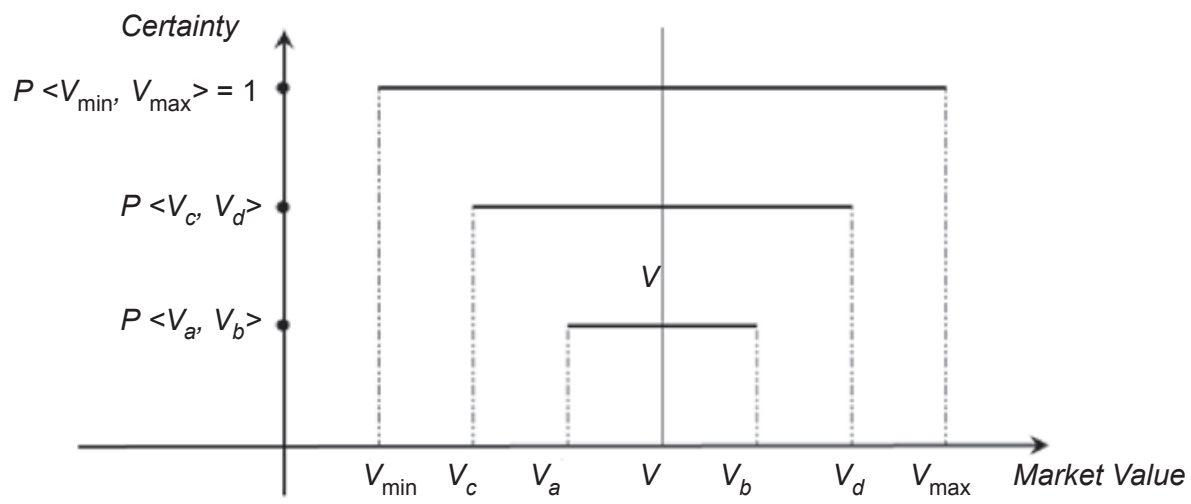

Figure 1. Demonstrative presentation of property value as a result of a simulation

Table 3. Types of parameters for the simulation of property valuation

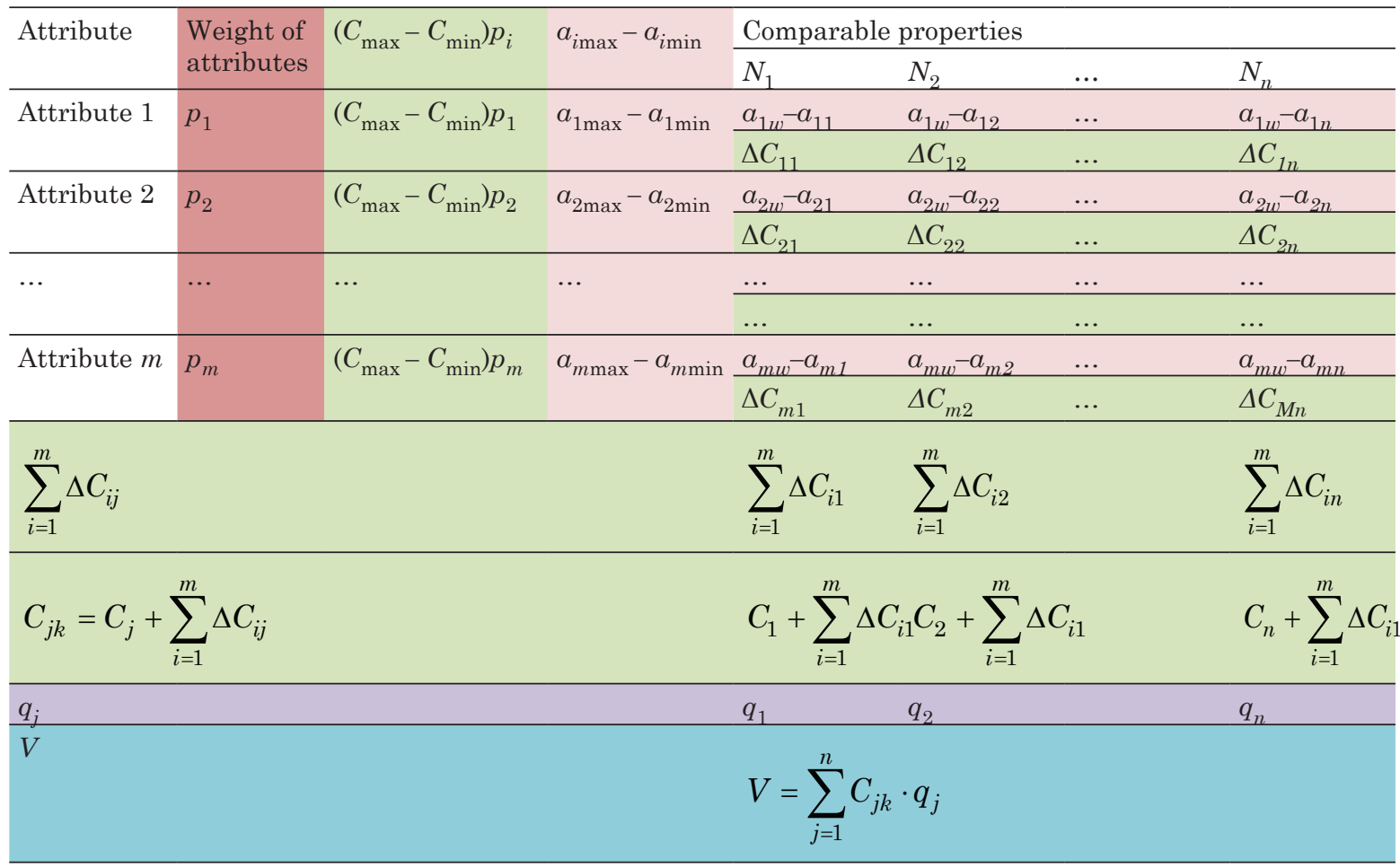

Key:

Input variables (primary simulation), subjected to standardization in order to fulfil the requirements:

$$
\sum_{i=1}^{m} p_{i}=1 \quad \sum_{j=1}^{n} q_{j}=1
$$

Values calculated based on primary simulation

Values that are not the subject of simulation

The end result calculated, based on primary simulation and based on values that are not the subject of simulation 
- the skewness of the distribution (reported as per cent at either end of range).

The key factor for simulation models is the way of expressing of the input data that are burdened with uncertainty. Mallinson and French (2000) suggested that the appropriate probability distribution would be a normal or bell distribution, whereas French and Gabrielli $(2004,2005)$ state, that the triangular approach is the most appropriate given the objectives.

The simulation in this paper has been applied within the pairwise comparison method where uncertainty was expressed through the assumption that the weights of attributes $\left(p_{i}\right)$ and the adjusted sales price reliability $\left(q_{j}\right)$ are not explicitly defined; they are only known as uniform distributed and assume the values: low 0.0 and high 1.0, where:

$$
\sum_{j=1}^{n} q_{j}=1 \text { and } \sum_{i=1}^{m} p_{i}=1 .
$$

Taking into consideration the indicators as in Table 1, the simulation of property valuation is presented in Table 3 .
The simulation made with the use of Crystal Ball software, using the data from Table 1, produced the outcome shown in Figure 2.

Taking into consideration the suggestions of French and Gabrielli (2005) Figure 3 shows the intervals of the property value corresponding to the level of certainty of $5 \%, 10 \%$ and $50 \%$ respectively.

The summary of the results obtained following the solution of the simulation model has been shown in Figure 6 in Section 5 .

\section{MODELLING OF PROPERTY VALUATION UNDER UNCERTAINTY WITH THE USE OF GAME THEORY}

The game theory can be used for sustainable decision-making; many authors have applied game theory to solve problems in construction engineering and management; i.a.: Peldschus and Zavadskas (2005) investigated fuzzy matrix game in construction, Lo et al. (2006) presented game theory model for evacuation, Sacks and Goldin (2007) tested lean management model for construction of high-rise apartment buildings using simulation game,

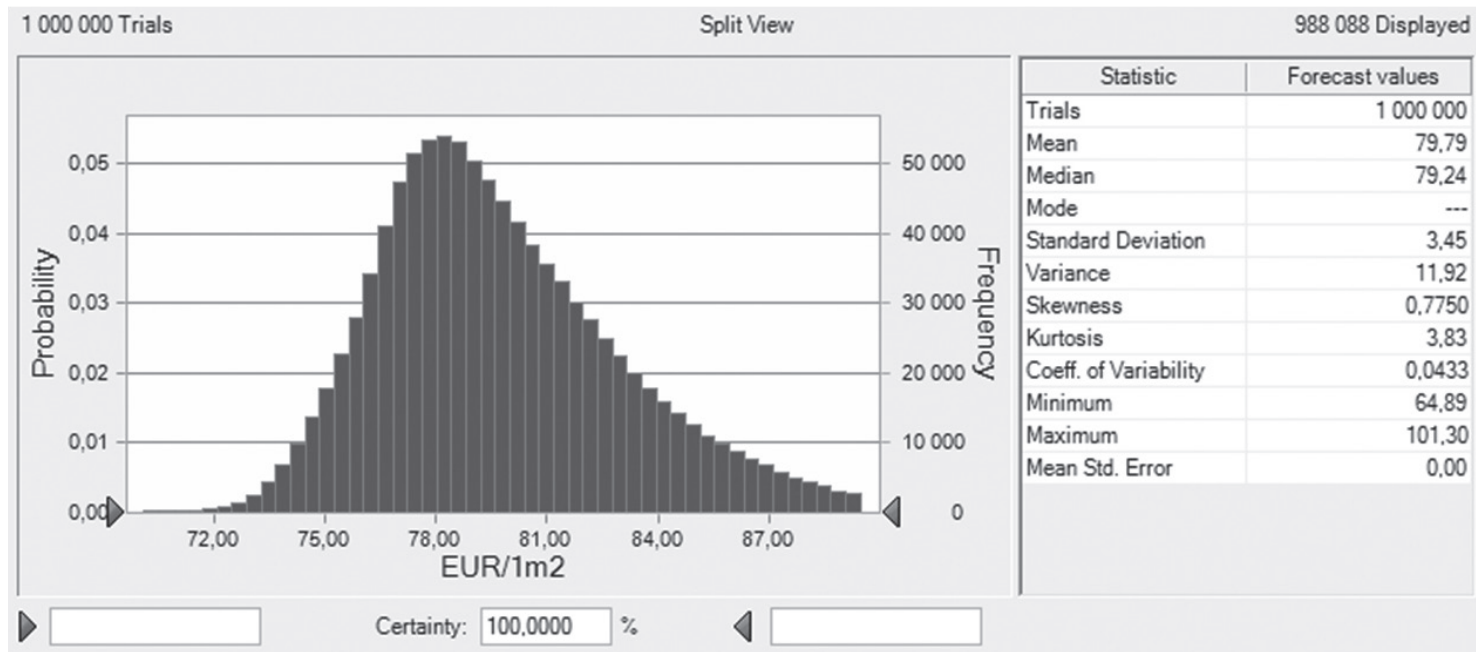

Figure 2. Market value distribution as an outcome of a simulation of the property valuation according to data from Table 1 

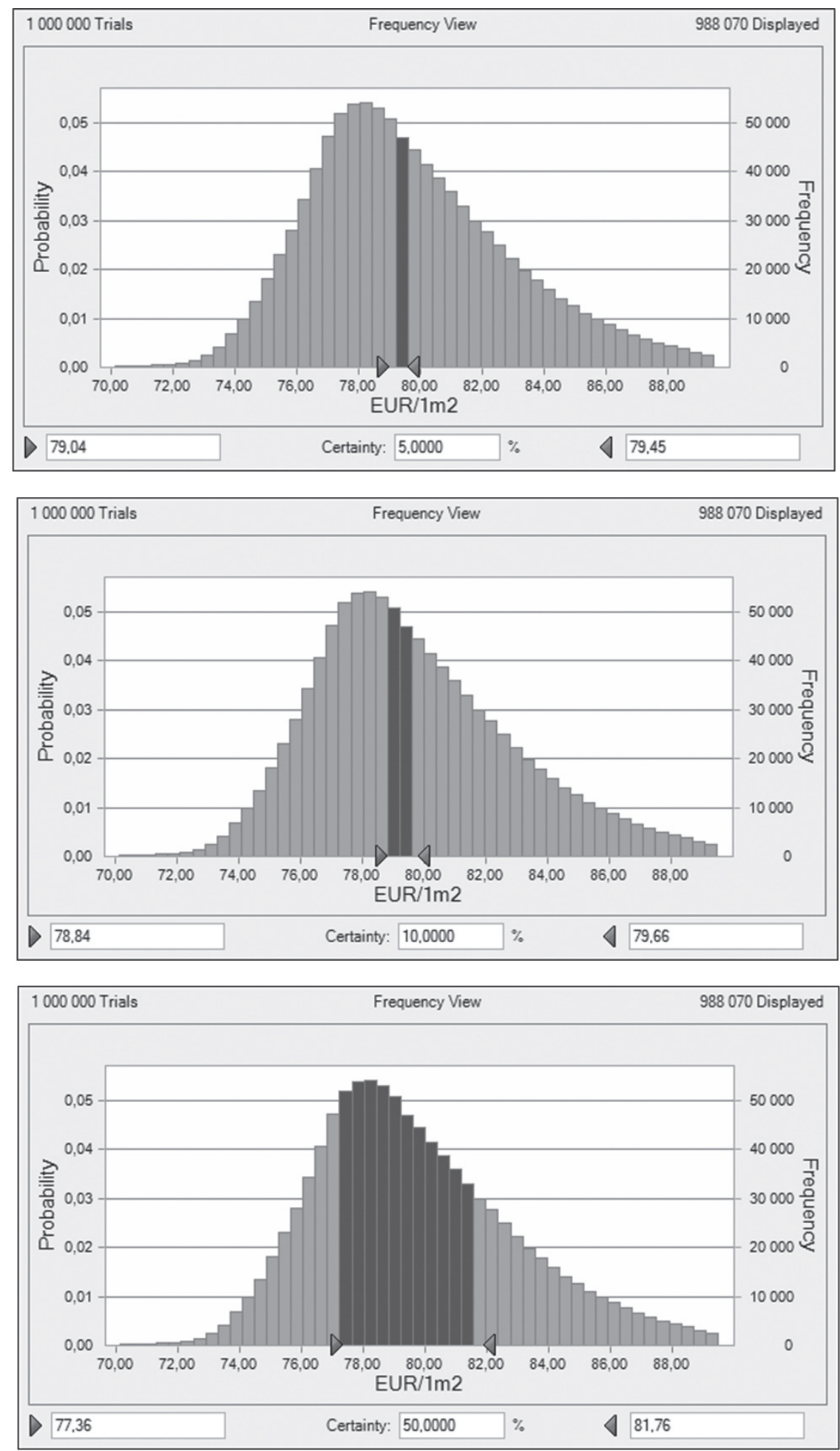

Figure 3 . The certainty range at $5 \%, 10 \%$ and $50 \%$ 
Gu et al. (2009) analysed Chinese strategies for energy-efficient housing development from an architect's perspective, Peldschus et al. (2010) demonstrate construction site selections, Miao et al. (2010) applied bi-level games for sustainable critical infrastructure system, Medineckienè et al. (2011) described model of dwelling selection, using fuzzy games theory, Chen et al. (2012) used bargaining-game theory to analysis of build-operate-transfer strategies, Zandi et al. (2012) proposed cooperative game-theoretic model for market segmentation.

A broad review of game theory rise, progress and applications is published by Peldschus (2008), Kapliński and Tamošaitienè (2010), Zavadskas and Turskis (2011), Peldschus and Zavadskas (2012).

As indicated in Section 2, the estimated market value of property depends on two parameters (weight of $p i$ property attributes and $q j$ sales price reliability), which in light of the presented remarks should be acknowledged as parameters determined in uncertainty (Meszek, 2007, 2008). The uncertainty taking place in the property valuation process may be interpreted in the context of decision situation where two parties affect (influence) the formation of the decision parameters $\left(p_{i}, q_{j}\right)$ in question, the values of which are known in the form of closed sets.

The issue of optimisation is oriented at the state of balance, being at the same time the expression of rational behaviour (action) of two parties in a decision situation. The so far existing research explicitly proved that the use of two-person zero sum strategic games in the form of, as we call it, games with Nature is also reasonable where there is no real conflict of interest between the parties in a decision situation. It has been proven that finding parameters corresponding to the saddle point (related to the equilibrium phenomenon) provides a satisfactory solution.
The strategic model representing the situation discussed is in the form of a two-person zero sum game, where its nature is more complex than the "game with Nature" - it corresponds to the essence of the "Nature with Nature" game.

For the purpose of this paper the two-person zero-sum game is used:

$$
\Gamma=(X, Y, a)
$$

its mixed extension $\Gamma_{m}$ in particular:

$$
\Gamma_{m}=(P, Q, H),
$$

where: $P\left(p_{1}, \ldots, p_{i}, \ldots, p_{m}\right)$ - strategy encompassing a set of weights of property individual attributes, whereas $\sum_{i=1}^{m} p_{i}=1,0 \leq p_{i} \leq 1 ; Q\left(q_{1}\right.$, $\left.\ldots, q_{i}, \ldots, q_{n}\right)$ - strategy encompassing a set of reliability of comparable property individual sale prices, whereas $\sum_{j=1}^{n} q_{j}=1, \quad 0 \leq q_{j} \leq 1 ; H$ $(p, q)$ - pay-off function.

For every mixed strategy $P$ and $Q$, the expectation $H$ can be expressed as:

$$
H(p, q)=\sum_{i=1}^{m} \sum_{j=1}^{n} p_{i} \cdot q_{j} \cdot h_{i j} .
$$

The basic problem to be solved in the property valuation process is the appropriate interpretation of game matrix elements $\left(h_{i j}\right)$. From the usability point of view (the game value must signify the property value), the game matrix elements must represent a corresponding category. Based on the logic of the theory of games, a principle was assumed that the $h_{i j}$ element denotes the hypothetical values of a valued property, determined for the cases where $p_{i}$ weights and $q_{j}$ reliability would be equal to 1, i.e. $h_{i j}=V$ for $p_{i}=1$ and $q_{j}=1$.

This kind of strategic game can be represented as matrix: 


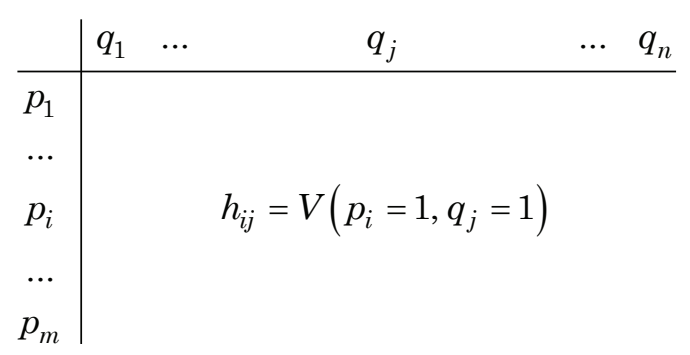

With the method of notation used in formula (3):

$$
h_{i j}=C_{j k}^{\prime}=C_{j}+\sum_{i=1}^{m} \Delta C_{i j}^{\prime},
$$

where: $\Delta C_{i j}{ }_{i j}$ - adjustments as in (4) formula, but each time with $p_{i}=100 \%$ weight:

$$
\Delta C_{i j}^{\prime}=\left(C_{\max }-C_{\min }\right) \cdot \frac{a_{i w}-a_{i j}}{a_{i \max }-a_{i \min }} .
$$

Taking that for each $i^{\text {th }}$ property attribute, quotient $\frac{\left(C_{\max }-C_{\min }\right)}{a_{i \max }-a_{i \min }}$ is a constant value, to substitute:

$$
\frac{\left(C_{\max }-C_{\min }\right)}{a_{i \max }-a_{i \min }}=A_{i},
$$

formula (10) can be presented as:

$$
C_{j k}^{\prime}=C_{j}+A_{i} \cdot\left(a_{i w}-a_{i j}\right) .
$$

In this situation, the initial decision making matrix shown in the form of (8) takes a form:
According to von Neumann and Morgenstern (1944), the search for a strategic model solution is based on the statement ...each twoplayer zero sum strategic game with a finite quantity of pure strategies $P$ and $Q$ has in its mixed extension, the game value $V$ and each player has at least one mixed strategy $p^{*} \in P$ or $\mathrm{q}^{*} \in Q$, that guarantees obtaining a result equal to the game value...

The above means that in each finished twoperson game, there is a pair of optimum mixed strategies $\left(p^{*}, q^{*}\right)$ representing the saddle point of game $\Gamma_{m}$.

Determining the value of game $V$ as the value of property $V_{1}$ and assuming that such value is minimized from the point of view of the first decision situation participant, the process of searching for an optimum mixed strategy consists in a game model solution for which the solution $p^{*}=\left(p_{1}{ }^{*}, \ldots, p_{m}{ }^{*}\right)$ and value $V_{1}$ are sought.

Due to the character of decision situation participants (NATURE I - participant influencing $p_{i}$ values and NATURE II - participant influencing $q_{j}$ values), the analysis must consider two games simultaneously based on similar payoff matrixes (differing by signs, or the interpretation of elements).

Game I: losses for participant No 1, profits for participant No 2; the saddle point prerequisite is then the rule:

$$
\begin{aligned}
& \max _{i} \min _{j} H(p, q)=\min _{j} \max _{i} H(p, q)= \\
& H\left(p^{*}, q^{*}\right)=V_{1} .
\end{aligned}
$$

$$
\begin{array}{c|ccccc} 
& q_{1} & \ldots & q_{j} & \ldots & q_{n} \\
\hline p_{1} & C_{1}+A_{1} \cdot\left(a_{1 w}-a_{11}\right) & \ldots & C_{j}+A_{1} \cdot\left(a_{1 w}-a_{1 j}\right) & \ldots & C_{n}+A_{1} \cdot\left(a_{1 w}-a_{1 n}\right) \\
\ldots & \ldots & \ldots & \ldots & \ldots & \ldots \\
p_{i} & C_{1}+A_{i} \cdot\left(a_{i w}-a_{i 1}\right) & \ldots & C_{j}+A_{i} \cdot\left(a_{i w}-a_{i j}\right) & \ldots & C_{n}+A_{i} \cdot\left(a_{i w}-a_{i n}\right) \\
\ldots & \ldots & \ldots & \ldots & \ldots & \ldots \\
p_{m} & C_{1}+A_{m} \cdot\left(a_{m w}-a_{m 1}\right) & \ldots & C_{j}+A_{m} \cdot\left(a_{m w}-a_{m j}\right) & \ldots & C_{n}+A_{m} \cdot\left(a_{m w}-a_{m n}\right)
\end{array}
$$


Game II: profits for participant No 1, losses for participant No 2; the saddle point prerequisite is then the rule:

$$
\begin{aligned}
& \max _{i} \min _{j} H(p, q)=\min _{j} \max _{i} H(p, q)= \\
& H\left(p^{*}, q^{*}\right)=V_{1} .
\end{aligned}
$$

of which: $V_{1}$ and $V_{2}$ - estimated property market value as a result of game I and II.

There are a number of methods of finding the optimum mixed strategies: graphic, algebraic or iteration simulation methods. In the case of many variable numbers, a useful tool to solve strategic models is the LEVI software. Version 4.0 of this software is described, i.a. by Zavadskas et al. (2008).

The following calculation process is based on data from Table 1. In view of a small amount of variables, the analysed issue is solved with the use of a linear model.

Taking that, according to formula (12):

$$
\begin{aligned}
& A_{1}=\frac{(90,00-70,00)}{4-1}=6,67 ; \\
& A_{2}=\frac{(90,00-70,00)}{5-1}=5,00
\end{aligned}
$$

and after substituting the rest of the data from Table 1, the result is the matrix in the form of $\left(\mathrm{EUR} / 1 \mathrm{~m}^{2}\right)$ :
The linear model that enables finding of the optimal mixed strategy leading to game value $V_{1}$ takes the form:

- Objective function: $V_{1} \rightarrow \max$

- limiting conditions:

$$
\begin{aligned}
& p_{1} \cdot 63,33+p_{2} \cdot 75,00 \geq V_{1} ; \\
& p_{1} \cdot 86,67+p_{2} \cdot 70,00 \geq V_{1} ; \\
& p_{1} \cdot 103,33+p_{2} \cdot 75,00 \geq V_{1} ; \\
& p_{1} \cdot 80,00+p_{2} \cdot 85,00 \geq V_{1} ; \\
& p_{1}+p_{2}=1,
\end{aligned}
$$

- boundary conditions:

$0 \leq p_{i} \leq 1$.

The linear model, however, that enables finding of the optimal mixed strategy leading to game value $V_{2}$ takes the form:

- objective function: $V_{2} \rightarrow \max$

- limiting conditions:

$$
\begin{aligned}
& q_{1} \cdot 63,33+q_{2} \cdot 86,67+q_{3} \cdot 103,33+q_{4} \cdot 80,00 \geq V_{2} ; \\
& q_{1} \cdot 75,00+q_{2} \cdot 70,00+q_{3} \cdot 75,00+q_{4} \cdot 85,00 \geq V_{2} ; \\
& q_{1}+q_{2}+q_{3}+q_{4}=1,
\end{aligned}
$$

- boundary conditions:

$0 \leq q_{j} \leq 1$.

$$
\begin{array}{c|ccccccc} 
& q_{1} & \ldots & q_{2} & \ldots & q_{3} & \ldots & q_{4} \\
\hline p_{1} & 70+6,67 \cdot(3-4) & \ldots & 80+6,67 \cdot(3-2) & \ldots & 90+6,67 \cdot(3-1) & \ldots & 80+6,67 \cdot(3-3) \\
\ldots & \ldots & \ldots & \ldots & \ldots & \ldots & \ldots & \ldots \\
p_{2} & 70+5,00 \cdot(2-1) & \ldots & 80+5,00 \cdot(2-4) & \ldots & 90+5,00 \cdot(2-5) & \ldots & 80+5,00 \cdot(2-1)
\end{array}
$$

and finally:

\begin{tabular}{c|ccccccc} 
& $q_{1}$ & $\ldots$ & $q_{2}$ & $\ldots$ & $q_{3}$ & $\ldots$ & $q_{4}$ \\
\hline$p_{1}$ & 63,33 & $\ldots$ & 86,67 & $\ldots$ & 103,33 & $\ldots$ & 80,00 \\
$\ldots$ & $\ldots$ & $\ldots$ & $\ldots$ & $\ldots$ & $\ldots$ & $\ldots$ & $\ldots$ \\
$p_{2}$ & 75,00 & $\ldots$ & 70,00 & $\ldots$ & 75,00 & $\ldots$ & 85,00
\end{tabular}


After the necessary transformations and solving of the models, the outcomes are:

$$
\begin{aligned}
& V_{1}=72.94 \mathrm{EUR} / 1 \mathrm{~m}^{2} \\
& V_{2}=83.50 \mathrm{EUR} / 1 \mathrm{~m}^{2}
\end{aligned}
$$

Taking into consideration a low number of variables in the analysed models their solutions can be presented graphically as shown in Figure 4.

The results were obtained by means of the game theory maintaining the characteristics of variables of an uncertain nature (their distributions of probability were unknown). They allow, however, further analyses, including, without limitations, the investment efficiency under uncertainty and the sensitivity analysis.

The range of values as a solution to the strategic model is dependent on the properties of the strategic game payoff matrix. In particular, it is dependent on the variability of the ratings of the individual characteristics and the degree of similarity of the compared property (subject property and comparable properties).

\section{CONCLUSIONS}

The comparison of the results of the analysed models is presented in the background of the simulation histogram (Figure 5), while the complex comparison, taking into account various ranges of certainty is presented in Figure 6.

The range of values, estimated by the solution of the strategic model does not have a logical contradiction with the solutions obtained from the simulation model.

Full equivalent of the uncertainty in the simulation model would be the solution at the certainty level of $100 \%$. As we can see in Figure 6 the range of the values obtained as a result of the solution of the strategic model is much narrower than that obtained as a result of the application of the simulation model for the certainty level of $100 \%$. This means that the solution of the strategic model is a significant supplement to the solutions available within the simulation model. This confirms, that game theory, compared with a simulation offers an appropriate approach to modelling of property valuation processes.

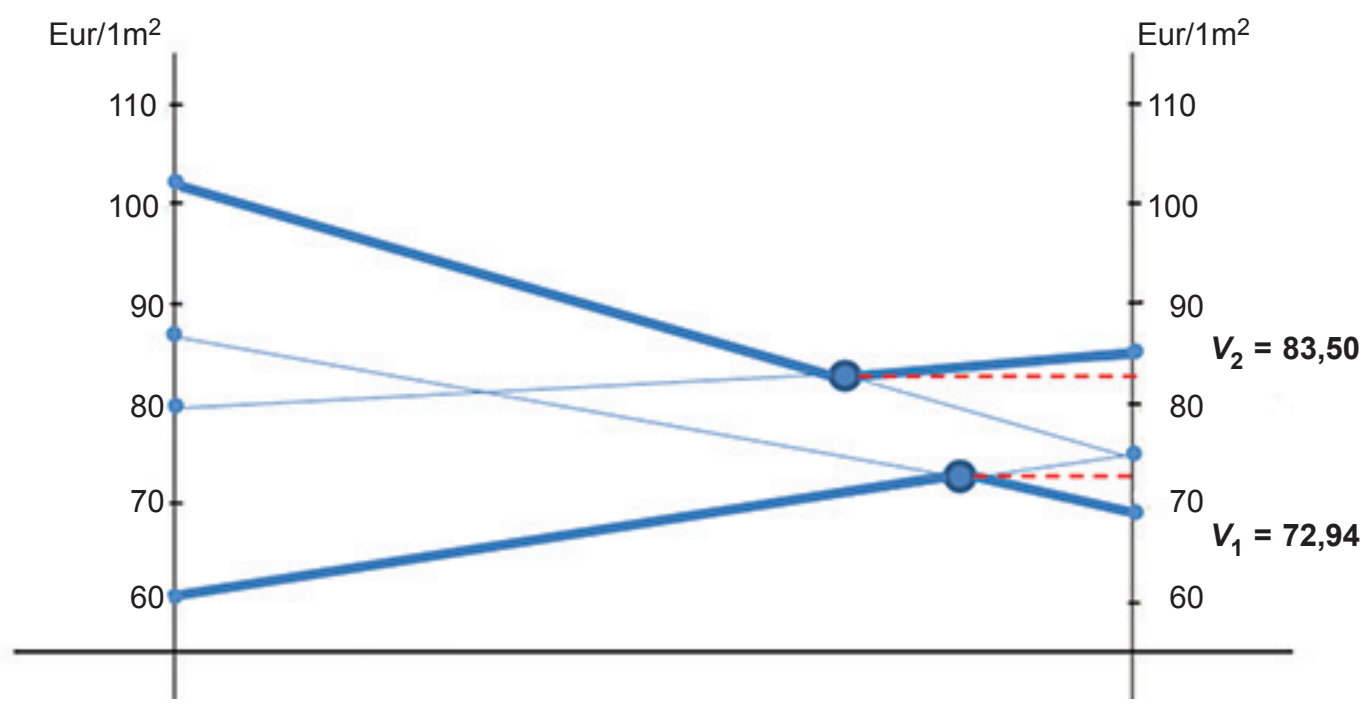

Figure 4. A graphic interpretation of the interval of property value as a result of a strategic model 


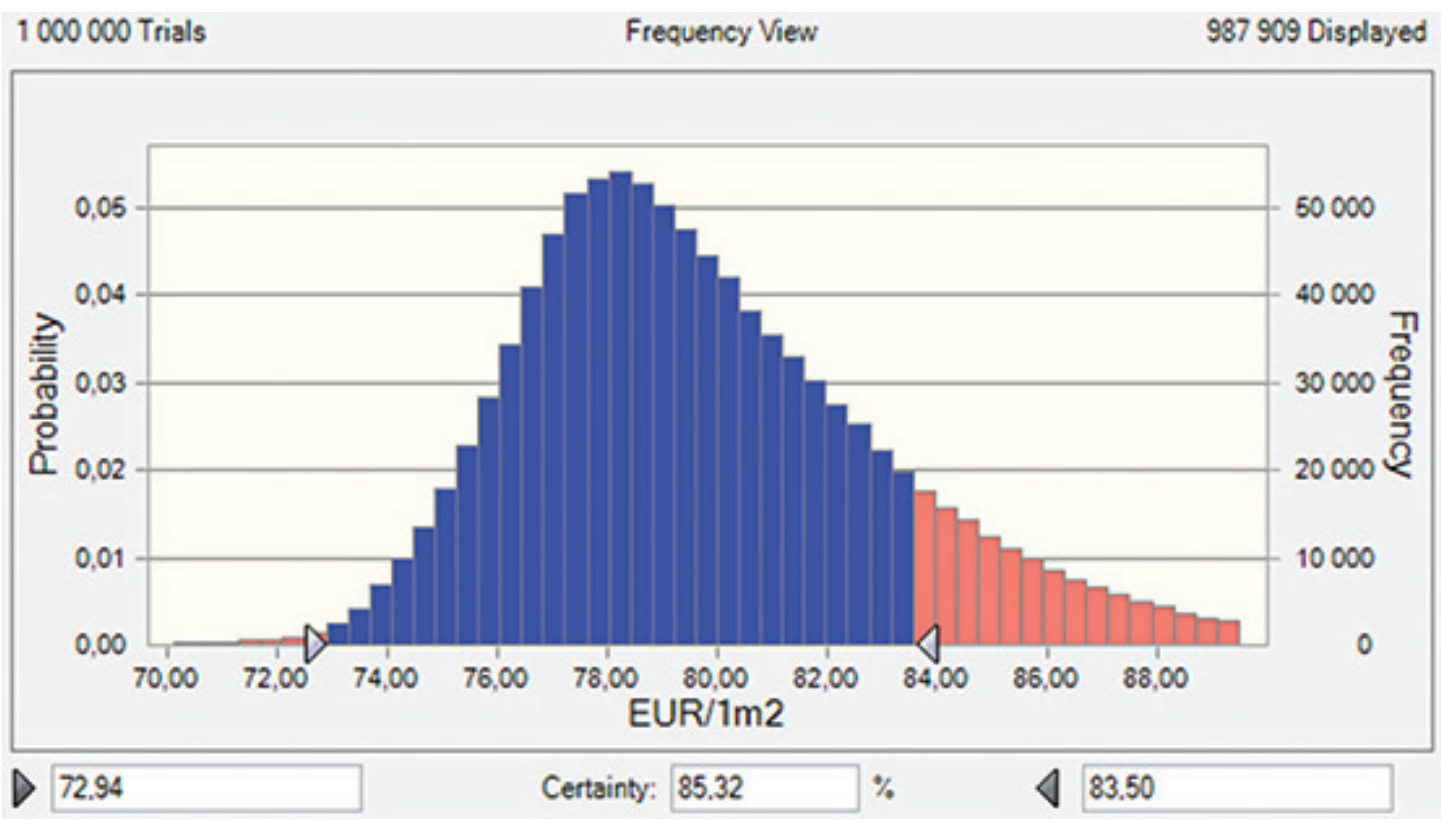

Figure 5. The interval of property value as a solution to the strategic model in the background of the simulation histogram

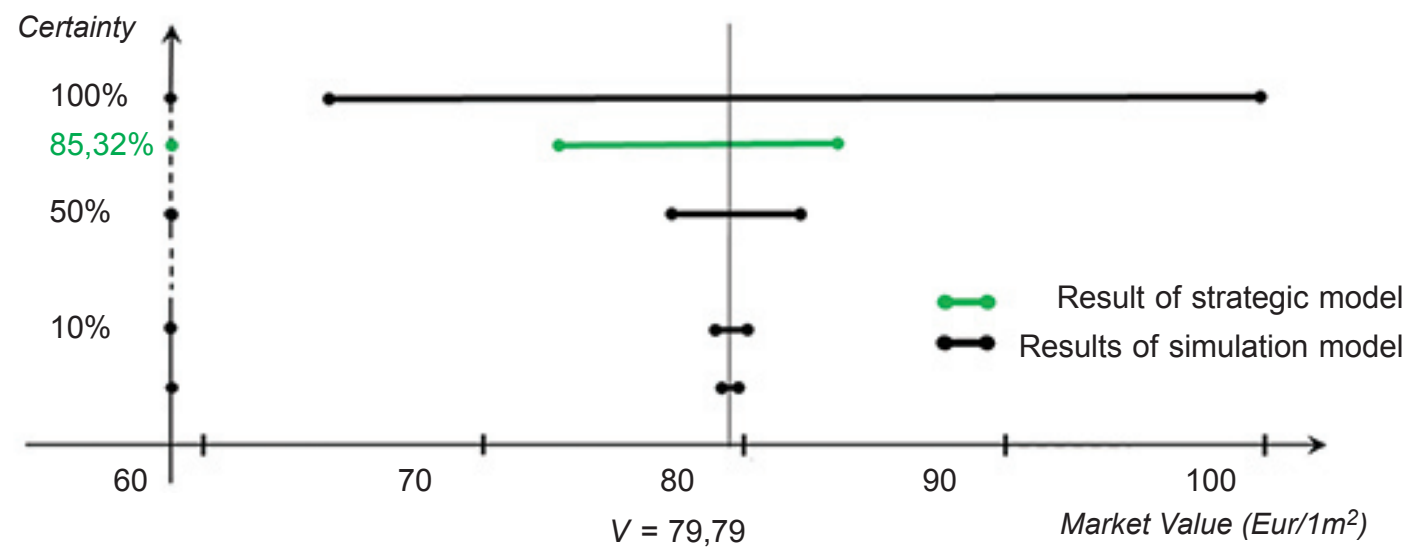

Figure 6. Comparison of the results obtained in effect of the applied simulation and the strategic model

The object of the modelling by the proposed methodology can be all urban real estate (undeveloped land, built-up property, real estate housing) for which property valuation is determined with the use of a sales comparison approach.
The solutions to the analysed models pave the way for the analysis of the investment efficiency, taking into account the uncertainty as a normal market feature deriving from the nature of a property. 


\section{REFERENCES}

Atherton, E., French, N. and Gabrielli, L. (2008) Decision theory and real estate development: a note on uncertainty, Journal of European Real Estate Research, 1(2), pp. 162-182. http:// dx.doi.org/10.1108/17539260810918730

Chen, T.-C., Lin, Y.-Ch. and Wang, L.-Ch. (2012) The analysis of BOT strategies based on game theory - case study on Taiwan's high speed railway project, Journal of Civil Engineering and Management, 18(5), pp. 662-674. http:// dx.doi.org/10.3846/13923730.2012.723329

Fama, E. (1965) Random walks in stock market prices, Financial Analyst Journal, 21(5), pp. 55-59. http://dx.doi.org/10.2469/faj.v21.n5.55

Fama, E. (1970) Efficient capital markets: A review of theory and empirical work, Journal of Finance, 25(2), pp. 383-417. http://dx.doi. org/10.2307/2325486

French, N. and Gabrielli, L. (2004) The uncertainty of valuation, Journal of Property Investment and Finance, 22(6), pp. 484-500. http://dx.doi. org/10.1108/14635780410569470

French, N. and Gabrielli, L. (2005) Discounted cash flow: Accounting for uncertainty, Journal of Property Investment and Finance, 23(1), pp.76-89. http://dx.doi. org/10.1108/14635780510575102

French, N. and Gabrielli, L. (2006) Uncertainty and feasibility studies: An Italian case study, Journal of Property Investment \& Finance, 24(1), pp. 49-67. http://dx.doi. org/10.1108/14635780610700732

Gu, Z., Vestbro, D. U., Wennersten, R. and Assefa, G. (2009) A study of Chinese strategies for energy-efficient housing developments from an architect's perspective, combined with Swedish experiences and game theory, Civil Engineering and Environmental Systems, 26(4), pp. 323-338. http://dx.doi. org/10.1080/10286600802151853

Joslin, A. (2005) An investigation into the expression of uncertainty in property valuations, Journal of Property Investment and Finance, 23(3), pp. 269-285. http://dx.doi. org/10.1108/14635780510599476

Kapliński, O. and Tamošaitienè, J. (2010) Game theory applications in construction engineering and management, Technological and Economic Development of Economy, 16(2), pp. 348-363. http://dx.doi.org/10.3846/tede.2010.22

Kucharska-Stasiak, E. (2008) Uncertainty of valuation in expropriation processes - the case of Poland, Nordic Journal of Surveying and Real Estate Research, 3, pp. 83-92.

Lo, S. M., Huang, H.C., Wang, P. and Yuen, K. K. (2006) A game theory based exit selection model for evacuation, Fire Safety Journal, 41(5), pp. 364-369. http://dx.doi.org/10.1016/j. firesaf.2006.02.003

Mallinson, M. and French, N. (2000) Uncertainty in property valuation, Journal of Property Investment and Finance, 18(1), pp. 13-32. http:// dx.doi.org/10.1108/14635780010316636

Medineckienė, M., Zavadskas, E. K. and Turskis, Z. (2011) Dwelling selection by applying fuzzy game theory, Archives of Civil and Mechanical Engineering, 11(3), pp. 681-697. http://dx.doi. org/10.1016/S1644-9665(12)60109-5

Meszek, W. (2007) Uncertainty phenomenon on property valuation, International Journal of Management and Decision Making, 8(56), pp. 575-585. http://dx.doi.org/10.1504/ IJMDM.2007.013419

Meszek, W. (2008) The analysis of property value increase as a result of infrastructural investment projects, International Journal of Environment and Pollution, 35(2-4), pp. 345-365. http://dx.doi.org/10.1504/IJEP.2008.021365

Miao, X., Yu, B., Xi, B. and Tang, Y. H. (2010) Modelling of bi-level games and incentives for sustainable critical infrastructure system, Technological and Economic Development of Economy, 16(3), pp. 365-379. http://dx.doi.org/10.3846/ tede. 2010.23

Peldschus, F. (2008) Experience of the game theory application in construction management, Technological and Economic Development of Economy, 14(4), pp. 531-545. http://dx.doi. org/10.3846/1392-8619.2008.14.531-545

Peldschus, F. and Zavadskas, E. K. (2005) Fuzzy matrix games multi-criteria model for decisionmaking in engineering, Informatica, 16(1), pp. 107-120.

Peldschus, F. and Zavadskas, E. K. (2012) Equilibrium approaches for construction processes - 
multi-objective decision making for construction projects, Bauingenieur, 87(5), pp. 210-215.

Peldschus, F., Zavadskas, E. K., Turskis, Z. and Tamosaitiene, J. (2010) Sustainable assessment of construction site by applying game theory, Inzinerine Ekonomika - Engineering Economics, 21(3), pp. 223-236.

Sacks, R. and Goldin, M. (2007) Lean management model for construction of high-rise apartment buildings, Journal of Construction Engineering and Management, 133(5), pp. 374384. http://dx.doi.org/10.1061/(ASCE)07339364(2007)133:5(374)

Siniak, N. and d'Amato, M. (2003) An application of fuzzy numbers for property investment and valuation, International Journal of Strategic Property Management, 7(3), pp.129-143.

The Carsberg Report (2002) Royal Institution of Chartered Surveyors (RICS), London.

The Mallinson Report (1994) Royal Institution of Chartered Surveyors (RICS), London.

von Neumann, J. and Morgenstern, O. (1944) Theory of games and economic behaviour. Princeton, NJ: Princeton University Press.
Wiśniewski, R. (2007) Efficient real estate market, Journal of the Polish Real Estate Scientific Society, 15(1-2), pp. 103-113.

Zandi, F., Tavana, M. and O'Connor, A. (2012) A strategic cooperative game-theoretic model for market segmentation with application to banking in emerging economies, Technological and Economic Development of Economy, 18(3), pp. 389-423. http://dx.doi.org/10.3846/20294913.2 012.688072

Zavadskas, E.K. and Turskis, Z. (2011) Multiple criteria decision making (MCDM) methods in economics: An overview, Technological and Economic Development of Economy, 17(2), pp. 397-427. http://dx.doi.org/10.3846/20294913.2 011.593291

Zavadskas E. K., Peldschus F. and Turskis Z. (2008) Multi-criteria optimization software LEVI-4.0 - A tool to support design and management in construction. In: The 25th International Symposium on Automation and Robotics in Construction (ISARC), Vilnius 2008, pp. 731-736. 